\title{
Achieving optimal adherence to medical therapy by telehealth: findings from the ORBITA medication adherence sub-study
}

\author{
David Thompson ${ }^{1}$, Rasha Al-lamee ${ }^{1}$, Michael Foley ${ }^{1}$, Hakim Dehbi ${ }^{2}$, Simon Thom ${ }^{1}$, Justin \\ Davies $^{1}$, Darrel Francis ${ }^{1}$, Prashanth Patel ${ }^{3}$, and Pankaj Gupta ${ }^{3}$ \\ ${ }^{1}$ Imperial College London \\ ${ }^{2}$ University College London \\ ${ }^{3}$ University Hospitals of Leicester NHS Trust
}

September 11, 2020

\begin{abstract}
Introduction The ORBITA trial of PCI versus a placebo procedure for patients with stable angina was conducted across 6 sites in the United Kingdom via home monitoring and telephone consultations. Patients underwent detailed assessment of medication adherence which allowed us to measure the efficacy of the implementation of the optimisation protocol and interpretation of the main trial endpoints. Methods Prescribing data were collected throughout the trial. Self-reported adherence was assessed, and urine samples collected at pre-randomisation and at follow-up for direct assessment of adherence using HPLC MS/MS. Results Self-reported adherence was $>96 \%$ for all drugs in both treatment groups at both stages. The percentage of samples in which drug was detected at pre-randomisation and at follow-up in the PCI vs. OMT groups respectively was: clopidogrel, $96 \%$ vs. $90 \%$ and $98 \%$ vs. $94 \%$; atorvastatin, $95 \%$ vs. $92 \%$ and $92 \%$ vs. $91 \%$; perindopril, $95 \%$ vs. $97 \%$ and $85 \%$ vs. $100 \%$; bisoprolol, $98 \%$ vs. $99 \%$ and $96 \%$ vs. $97 \%$; amlodipine, $99 \%$ vs. $99 \%$ and $94 \%$ vs. $96 \%$; nicorandil, $98 \%$ vs. $96 \%$ and $94 \%$ vs. $92 \%$; ivabradine, $100 \%$ vs. $100 \%$ and $100 \%$ vs. $100 \%$; and ranolazine, $100 \%$ vs. $100 \%$ and $100 \%$ vs. $100 \%$. Conclusions Adherence levels were high throughout the study when quantified by self-reporting methods and similarly high proportions of drug were detected by urinary assay. The results indicate successful implementation of the optimisation protocol delivered by telephone, an approach that could serve as a model for treatment of chronic conditions, particularly as consultations are increasingly conducted online.
\end{abstract}

Achieving optimal adherence to medical therapy by telehealth: findings from the ORBITA medication adherence sub-study

D Thompson ${ }^{1,2}$

R Al-Lamee ${ }^{1}$

M Foley ${ }^{1}$

H M Dehbi ${ }^{3}$

S Thom ${ }^{1}$

J E Davies ${ }^{1}$

D P Francis ${ }^{1}$

P Patel ${ }^{4,5,6}$

P Gupta ${ }^{4,5,6}$ 
On behalf of the ORBITA Investigators*.

1. National Heart and Lung Institute, Imperial College London

2. Institute of Cardiovascular Science, University College London

3. Comprehensive Clinical Trials Unit at UCL, University College London

4. Department of Chemical Pathology and Metabolic Diseases, University Hospitals of Leicester

5. Department of Cardiovascular Sciences, University of Leicester

6. NIHR Leicester Biomedical Research Unit in Cardiovascular Disease

Corresponding Author:

Dr. David Thompson

UCL Institute of Cardiovascular Science

Gower Street

London WC1E 6BT

Email:dm.thompson@ucl.ac.uk

\section{Abstract}

\section{Introduction}

The ORBITA trial of PCI versus a placebo procedure for patients with stable angina was conducted across 6 sites in the United Kingdom via home monitoring and telephone consultations. Patients underwent detailed assessment of medication adherence which allowed us to measure the efficacy of the implementation of the optimisation protocol and interpretation of the main trial endpoints.

\section{Methods}

Prescribing data were collected throughout the trial. Self-reported adherence was assessed, and urine samples collected at pre-randomisation and at follow-up for direct assessment of adherence using HPLC MS/MS.

\section{Results}

Self-reported adherence was $>96 \%$ for all drugs in both treatment groups at both stages. The percentage of samples in which drug was detected at pre-randomisation and at follow-up in the PCI vs. OMT groups respectively was: clopidogrel, $96 \%$ vs. $90 \%$ and $98 \%$ vs. $94 \%$; atorvastatin, $95 \%$ vs. $92 \%$ and $92 \%$ vs. $91 \%$; perindopril, $95 \%$ vs. $97 \%$ and $85 \%$ vs. $100 \%$; bisoprolol, $98 \%$ vs. $99 \%$ and $96 \%$ vs. $97 \%$; amlodipine, $99 \%$ vs. $99 \%$ and $94 \%$ vs. $96 \%$; nicorandil, $98 \%$ vs. $96 \%$ and $94 \%$ vs. $92 \%$; ivabradine, $100 \%$ vs. $100 \%$ and $100 \%$ vs. $100 \%$; and ranolazine, $100 \%$ vs. $100 \%$ and $100 \%$ vs. $100 \%$.

\section{Conclusions}

Adherence levels were high throughout the study when quantified by self-reporting methods and similarly high proportions of drug were detected by urinary assay. The results indicate successful implementation of the optimisation protocol delivered by telephone, an approach that could serve as a model for treatment of chronic conditions, particularly as consultations are increasingly conducted online.

\section{Introduction}

The ORBITA (Objective Randomized Blinded Investigation with optimal medical Therapy of Angioplasty for stable angina) trial showed that the increment in exercise capacity following percutaneous coronary intervention (PCI) was lower than expected and not statistically different to the effect of a placebo procedure in patients with stable coronary artery disease $(\mathrm{CAD})$ receiving optimal medical therapy $(\mathrm{OMT})^{1}$. Patients 
were eligible for enrolment if they had single-vessel, angiographically-significant coronary artery disease for which PCI was clinically indicated on a pre-trial invasive coronary angiogram. Following enrolment patients commenced a 6 -week medication optimisation phase during which their risk reduction and antianginal medication was optimised in accordance with clinical guidelines ${ }^{2}$. Some commentators highlighted that optimisation of medical therapy in ORBITA was intensive and could not be easily replicated in clinical practice $^{3}$. Indeed, in clinical practice, guideline-directed medication optimisation prior to PCI is variable. Analysis of the CathPCI registry in the USA in 2011 showed that OMT (defined as aspirin, statin, a beta-blocker or documented intolerance) was achieved in just $44 \%$ of patients prior to $\mathrm{PCI}^{4}$. A Canadian registry study in 2014 showed that OMT (defined in this instance as statin, beta-blocker, and either an angiotensin-converting enzyme inhibitor or an angiotensin II receptor blocker) was achieved in only $33.9 \%$ of patients prior to $\mathrm{PCI}^{5}$. ORBITA was conducted in the UK, where targets for heart rate and blood pressure were achieved in less than $50 \%$ of patients when optimising anti-anginal therapy prior to elective $\mathrm{PCI}^{6}$. A single consultant cardiologist and research fellow (RAL) conducted the 6-week medication optimisation in telephone clinics one to three times per week. The trial patients were expected to achieve optimisation in a short, intensive period to ensure that patients did not experience undue delays in accessing PCI compared to usual clinical care. In addition to documentation of patterns of prescribing, patients' self-reported adherence to therapy and urine samples for direct detection of urinary metabolites were collected. In this way the efficacy of the OMT protocol and possible treatment imbalances between the groups that could affect the main study endpoints could be assessed. Quantifying adherence in detail also allowed evaluation of any changes in medication taking behaviour that may have arisen following PCI.

\section{Methods}

\section{Eligibility, study design and organisation.}

The eligibility criteria for ORBITA and study sites have been described elsewhere ${ }^{7}$. Patients with stable coronary artery disease attributable to single-vessel coronary artery disease were eligible to participate. Detailed medication prescribing and adherence assessments were carried out on all ORBITA participants. Once enrolled patients entered the medication optimisation phase. Following this 6-week phase, patients travelled to the study coordinating centre, Imperial College Healthcare NHS Trust, London, UK, for further clinical assessment including cardiopulmonary exercise testing and dobutamine stress echocardiography. The research protocol coronary angiogram was then carried out at their local centre, during which they were randomised to either PCI or a placebo procedure. After 6-weeks of blinded follow-up patients returned for repeat testing and study unblinding at the coordinating centre. A favourable review of the study protocol was obtained from the London Central Research Ethics Committee and the trial received support from the NIHR Imperial Biomedical Research Centre, Foundation for Circulatory Health, Imperial College Healthcare Charity, Philips Volcano, NIHR Barts Biomedical Research Centre.

\section{Personnel}

Two research fellows were essential to the study team and had distinct predefined roles. The unblinded fellow (RAL) provided support in the catheterisation laboratory for the randomisation procedure and in doing so became unblinded to the randomised treatment assignment. The blinded fellow (DT) remained so throughout the study and performed all pre-randomisation and follow-up tests. RAL was based primarily in the coronary catheter laboratory and was responsible for enrolling new patients to the study as well as providing support to the site teams. RAL was the main clinical point of contact for patients from enrolment and throughout the medication optimisation phase until after randomisation. This enabled RAL to engage patients at enrolment and give instructions regarding standardised recording of home blood pressure, provide medication prescriptions and resolve issues with dispensing. RAL scheduled weekly telephone reviews with patients for introduction and titration of cardiovascular preventive and anti-anginal therapy. DT met patients for the first time at the pre-randomisation assessment visit in London and became the main clinical point of contact for patients in the blinded follow-up period. DT was not involved in medication optimisation but 
carried out a final check of protocol adherence before the patients proceeded to randomisation. The authors confirm that the PI for this study is Professor Darrel Francis and that he had direct clinical responsibility for patients.

\section{Optimisation of medical therapy}

At the enrolment assessment current medications were recorded before commencing the medical optimisation phase. Medications and doses were entered on the study electronic case report form and patients were provided with a home blood pressure monitor, an individualised prescription for optimised administration of medications, counselling regarding medication adherence and were asked to perform daily home measurements. Medications were then optimised during clinician assessments with RAL one to three times per week, in accordance with the study protocol.

\section{Endpoints}

Self-reported adherence was assessed for each medication by asking each patient "How many days in the preceding week did you take this medication?" 8 This was carried out at pre-randomisation and at follow-up. Direct assessment of medication adherence was carried out using high performance liquid chromatographytandem mass spectrometry (HPLC MS/MS) for detection of protocol-directed medications (Table 1) in urine samples at both pre-randomisation and at follow-up stages. The HPLC MS/MS methodology has been previously described ${ }^{9}$. All adherence data were collected as pre-specified secondary study endpoints.

\section{Analysis}

We present descriptive statistics for prescribed drug as a percentage of number of patients at each stage, self-reported adherence scores and percentages of detected drug present in the tested samples.

Table 1 ORBITA medical therapy protocol drugs detectable by HPLC MS/MS

\begin{tabular}{ll}
\hline Drug & \\
\hline Aspirin & Not screened \\
Other antiplatelet agents: & \\
Clopidogrel & Screened \\
Prasurgel & Not screened \\
Ticagrelor & Not screened \\
Atorvastatin & Screened \\
Perindopril & Screened \\
Bisoprolol & Screened \\
Amlodipine & Screened \\
Isosorbide mononitrate & Not Screened \\
Nicorandil & Screened \\
Ivabradine & Screened \\
Ranolazine & Screened \\
\hline
\end{tabular}

\section{Results}

The baseline characteristics of the ORBITA participants are previously described ${ }^{1}$. The groups were evenly balanced and prescribing data were available for all 200 randomised participants. Self-reported adherence data and HPLC MS/MS urinalysis data were present for 158 and 195 patients respectively. 


\section{Optimisation of medical therapy}

At enrolment, prior to optimisation, $82(78 \%)$ and $75(79 \%)$ of patients in the PCI and placebo groups respectively were prescribed aspirin, $71(68 \%)$ and $66(69 \%)$ patients were prescribed a statin and $20(19 \%)$ and $28(29 \%)$ patients were prescribed [?] 2 anti-anginal agents. By pre-randomization which signifies the end of OMT (Table 2) 102 and (97\%) and $92(97 \%)$ patients were prescribed aspirin, $100(95 \%)$ and $91(96 \%)$ were prescribed atorvastatin or other statin and $90(86 \%)$ and $93(98 \%)$ patients were prescribed [?] 2 antianginal agents, in the PCI and placebo groups respectively. Most patients were prescribed two anti-platelet agents, in keeping with guideline-directed clinical practice for elective PCI. The most commonly prescribed, protocol-directed anti-anginal agents were calcium channel blockers - prescribed for 95 (90\%) patients that received PCI and 87 (92\%) patients that received placebo. Prescription of anti-anginal agents was evenly balanced between the groups, both at pre-randomisation and at follow-up and there was no notable change in prescribing from pre-randomisation to follow-up within groups.

\section{Self-reported medication adherence}

Self-reported adherence was $>96 \%$ for all drugs in both treatment groups at both stages (Table 2).

\section{Urinary HPLC MS/MS}

The proportion of expected drug detected was $>90 \%$ for all first-choice, protocol-directed medicines at both stages. Conversely, percentage adherence below $80 \%$ was not demonstrated for any drug at pre-randomisation and was only apparent in patients that were prescribed an alternative statin and who underwent urinary drug detection by HPLC MS/MS at follow-up: 11 of 14 (73\%) patients in the PCI group and 2 of 3 (67\%) patients in the placebo group.

\begin{tabular}{|c|c|c|c|c|c|c|c|c|c|c|c|c|c|}
\hline & Enrolm & efinhrolr & $\begin{array}{l}\text { Pre- } \\
\text { enatndom }\end{array}$ & $\begin{array}{l}\text { Pre- } \\
\text { aisathidom }\end{array}$ & $\begin{array}{l}\text { Pre- } \\
\text { lisanhidomm }\end{array}$ & $\begin{array}{l}\text { Pre- } \\
\text { iisantidoon }\end{array}$ & $\begin{array}{l}\text { Pre- } \\
\text { Aisaatibom }\end{array}$ & $\begin{array}{l}\text { Pre- } \\
\text { Pisantibom }\end{array}$ & $\begin{array}{l}\text { Follow- } \\
\text { aisption }\end{array}$ & $\begin{array}{l}\text { Follow- } \\
\text { up }\end{array}$ & $\begin{array}{l}\text { Follow- } \\
\text { up }\end{array}$ & $\begin{array}{l}\text { Follow- } \\
\text { up }\end{array}$ & $\begin{array}{l}\text { Fol } \\
\text { up }\end{array}$ \\
\hline & PCI & Placebc & PCI & PCI & PCI & Place & oPlacebo & oPlacebo & oPCI & PCI & PCI & $\mathrm{Pl}$ & $\mathrm{oP}$ \\
\hline & $\begin{array}{l}(\mathrm{N}=10 \\
\text { Prescri }\end{array}$ & $\begin{array}{l}5(\mathrm{~N}=95) \\
\text { bEdescri }\end{array}$ & $\begin{array}{l}(\mathrm{N}=105 \\
\text { bEdescri }\end{array}$ & $\begin{array}{l}5)(N=10 \\
\text { bisellf- }\end{array}$ & $\begin{array}{c}5 \gamma(N=105 \\
\text { HPLC }\end{array}$ & $\begin{array}{l}5 / \mathrm{N}= \\
\text { Pres }\end{array}$ & $\begin{array}{l}(\mathrm{N}=95) \\
\text { bsellf- }\end{array}$ & $\begin{array}{l}(\mathrm{N}=95) \\
\text { HPLC }\end{array}$ & $\begin{array}{l}(\mathrm{N}=105 \\
\text { Prescril }\end{array}$ & $\begin{array}{l}5 \times N=105 \\
\text { boellf- }\end{array}$ & $\begin{array}{c}5 / \mathrm{N}=105 \\
\text { HPLC }\end{array}$ & & bs \\
\hline & $(\%)$ & $(\%)$ & & $\begin{array}{l}\text { reportec } \\
\text { [days } \\
(\%)]\end{array}$ & $\begin{array}{l}\mathrm{dMS} / \mathrm{MS} \\
\text { de- } \\
\text { tected }\end{array}$ & & $\begin{array}{l}\text { reportec } \\
\text { [days } \\
(\%)]\end{array}$ & $\begin{array}{l}\text { dMS/MS } \\
\text { de- } \\
\text { tected } \\
{[\%} \\
\text { sam- } \\
\text { ples } \\
\text { tested] }\end{array}$ & & $\begin{array}{l}\text { reportec } \\
{[\text { days }} \\
(\%)]\end{array}$ & $\begin{array}{l}\text { dMS /MS } \\
\text { de- } \\
\text { tected }\end{array}$ & & \\
\hline . & $\begin{array}{l}82 \\
(78 \%)\end{array}$ & $\begin{array}{l}75 \\
(79 \%)\end{array}$ & $\begin{array}{l}102 \\
(97 \%)\end{array}$ & $\begin{array}{l}6.95 \\
(99.29 \\
\%)\end{array}$ & - & $\begin{array}{l}92 \\
(97 \%)\end{array}$ & $\begin{array}{l}6.86 \\
(98.00 \\
\%)\end{array}$ & - & $\begin{array}{l}103 \\
(98 \%)\end{array}$ & $\begin{array}{l}6.93 \\
(99.00 \\
\%)\end{array}$ & - & $\begin{array}{l}91 \\
(96 \%)\end{array}$ & \\
\hline clopidogr & $\begin{array}{l}\mathrm{r} A \mathrm{D} \\
(38 \%)\end{array}$ & $\begin{array}{l}36 \\
(38 \%)\end{array}$ & $\begin{array}{l}102 \\
(97 \%)\end{array}$ & $\begin{array}{l}7.00 \\
(100.00 \\
\%)\end{array}$ & $\begin{array}{l}66 \\
(96 \\
\%)\end{array}$ & $\begin{array}{l}88 \\
(93 \%)\end{array}$ & $\begin{array}{l}7.00 \\
(100.00 \\
\%)\end{array}$ & $\begin{array}{l}52 \\
(90 \\
\%)\end{array}$ & $\begin{array}{l}102 \\
(97 \%)\end{array}$ & $\begin{array}{l}6.97 \\
(99.57 \\
\%)\end{array}$ & $\begin{array}{l}91 \\
(98 \\
\%)\end{array}$ & $\begin{array}{l}88 \\
(93 \%)\end{array}$ & \\
\hline $\begin{array}{l}\text { other } \\
\text { AP }\end{array}$ & $\begin{array}{l}2 \\
(2 \%)\end{array}$ & $\begin{array}{l}4 \\
(4 \%)\end{array}$ & $\begin{array}{l}3 \\
(2 \%)\end{array}$ & $\begin{array}{l}7.00 \\
(100.00 \\
\%)\end{array}$ & - & $\begin{array}{l}6 \\
(6 \%)\end{array}$ & $\begin{array}{l}7.00 \\
(100.00 \\
\%)\end{array}$ & - & $\begin{array}{l}3 \\
(3 \%)\end{array}$ & $\begin{array}{l}7.00 \\
(100.00 \\
\%)\end{array}$ & - & $\begin{array}{l}6 \\
(6 \%)\end{array}$ & \\
\hline atorvasta & $\begin{array}{l}(47 \%) \\
(490)\end{array}$ & $\begin{array}{l}47 \\
(49 \%)\end{array}$ & $\begin{array}{l}88 \\
(84 \%)\end{array}$ & $\begin{array}{l}6.82 \\
(97.43 \\
\%)\end{array}$ & $\begin{array}{l}82 \\
(95 \\
\%)\end{array}$ & $\begin{array}{l}86 \\
(91 \%)\end{array}$ & $\begin{array}{l}7.00 \\
(100.00 \\
\%)\end{array}$ & $\begin{array}{l}68 \\
(92 \\
\%)\end{array}$ & $\begin{array}{l}86 \\
(82 \%)\end{array}$ & $\begin{array}{l}6.83 \\
(97.57 \\
\%)\end{array}$ & $\begin{array}{l}72 \\
(92 \\
\%)\end{array}$ & $\begin{array}{l}86 \\
(91 \%)\end{array}$ & 6 \\
\hline
\end{tabular}




\begin{tabular}{|c|c|c|c|c|c|c|c|c|c|c|c|c|c|}
\hline & Enroln & hroln & re- & $\begin{array}{l}\text { Pre- } \\
\text { lisathidom }\end{array}$ & $\begin{array}{l}\text { Pre- } \\
\text { hissatidor }\end{array}$ & $\begin{array}{c}\text { Pre- } \\
\text { nisathidon }\end{array}$ & $\begin{array}{l}\text { Pre- } \\
\text { aisathidom }\end{array}$ & $\begin{array}{l}\text { Pre- } \\
\text { hissathidor }\end{array}$ & $\begin{array}{c}\text { Follow- } \\
\text { nisption }\end{array}$ & $\begin{array}{l}\text { Follow- } \\
\text { up }\end{array}$ & $\begin{array}{l}\text { Follow- } \\
\text { up }\end{array}$ & $\begin{array}{l}\text { Follow- } \\
\text { up }\end{array}$ & $\begin{array}{l}\text { Foll } \\
\text { up }\end{array}$ \\
\hline $\begin{array}{l}\text { ter } \\
\text { tin }\end{array}$ & $\begin{array}{l}22 \\
(21 \%)\end{array}$ & $\begin{array}{l}19 \\
(20 \%)\end{array}$ & $\begin{array}{l}12 \\
(11 \%)\end{array}$ & $\begin{array}{l}7.00 \\
(100.00 \\
\%)\end{array}$ & $\begin{array}{l}10 \\
(100 \\
\%)\end{array}$ & $\begin{array}{l}5 \\
(5 \%)\end{array}$ & $\begin{array}{l}7.00 \\
(100.00 \\
\%)\end{array}$ & $\begin{array}{l}6 \\
(100 \\
\%)\end{array}$ & $\begin{array}{l}15 \\
(14 \%)\end{array}$ & $\begin{array}{l}6.89 \\
(98.43 \\
\%)\end{array}$ & $\begin{array}{l}11 \\
(79 \\
\%)\end{array}$ & $\begin{array}{l}5 \\
(5 \%)\end{array}$ & $\begin{array}{l}6.67 \\
(95 \\
\%)\end{array}$ \\
\hline \multicolumn{2}{|c|}{$\begin{array}{l}\text { perindopr4l } \\
\qquad(4 \%)\end{array}$} & $\begin{array}{l}6 \\
(6 \%)\end{array}$ & $\begin{array}{l}37 \\
(35 \%)\end{array}$ & $\begin{array}{l}7.00 \\
(100.00 \\
\%)\end{array}$ & $\begin{array}{l}37 \\
(95 \\
\%)\end{array}$ & $\begin{array}{l}37 \\
(39 \%)\end{array}$ & $\begin{array}{l}6.91 \\
(98.71 \\
\%)\end{array}$ & $\begin{array}{l}33 \\
(97 \\
\%)\end{array}$ & $\begin{array}{l}37 \\
(35 \%)\end{array}$ & $\begin{array}{l}6.92 \\
(98.86 \\
\%)\end{array}$ & $\begin{array}{l}29 \\
(85 \\
\%)\end{array}$ & $\begin{array}{l}37 \\
(39 \%)\end{array}$ & \\
\hline \multicolumn{2}{|c|}{$\begin{array}{l}\text { bisoproloB2 } \\
\qquad(30 \%)\end{array}$} & $\begin{array}{l}25 \\
(26 \%)\end{array}$ & $\begin{array}{l}83 \\
(79 \%)\end{array}$ & $\begin{array}{l}7.00 \\
(100.00 \\
\%)\end{array}$ & $\begin{array}{l}79 \\
(98 \\
\%)\end{array}$ & $\begin{array}{l}74 \\
(78 \%)\end{array}$ & $\begin{array}{l}7.00 \\
(100.00 \\
\%)\end{array}$ & $\begin{array}{l}66 \\
(99 \\
\%)\end{array}$ & $\begin{array}{l}83 \\
(87 \%)\end{array}$ & $\begin{array}{l}6.88 \\
(98.29 \\
\%)\end{array}$ & $\begin{array}{l}73 \\
(96 \\
\%)\end{array}$ & $\begin{array}{l}74 \\
(78 \%)\end{array}$ & $\begin{array}{l}6.80 \\
(97.1 \\
\%)\end{array}$ \\
\hline \multicolumn{2}{|c|}{$\begin{array}{l}\text { amlodipines } \\
\qquad(24 \%)\end{array}$} & $\begin{array}{l}31 \\
(33 \%)\end{array}$ & $\begin{array}{l}89 \\
(85 \%)\end{array}$ & $\begin{array}{l}7.00 \\
(100.00 \\
\%)\end{array}$ & $\begin{array}{l}86 \\
(99 \\
\%)\end{array}$ & $\begin{array}{l}80 \\
(84 \%)\end{array}$ & $\begin{array}{l}7.00 \\
(100.00 \\
\%)\end{array}$ & $\begin{array}{l}70 \\
(99 \\
\%)\end{array}$ & $\begin{array}{l}90 \\
(86 \%)\end{array}$ & $\begin{array}{l}6.88 \\
(98.29 \\
\%)\end{array}$ & $\begin{array}{l}77 \\
(94 \\
\%)\end{array}$ & $\begin{array}{l}77 \\
(81 \%)\end{array}$ & \\
\hline ISMN & $\begin{array}{l}26 \\
(25 \%)\end{array}$ & $\begin{array}{l}23 \\
(24 \%)\end{array}$ & $\begin{array}{l}69 \\
(66 \%)\end{array}$ & $\begin{array}{l}6.93 \\
(99.00 \\
\%)\end{array}$ & - & $\begin{array}{l}66 \\
(69 \%)\end{array}$ & $\begin{array}{l}7.00 \\
(100.00 \\
\%)\end{array}$ & - & $\begin{array}{l}69 \\
(66 \%)\end{array}$ & $\begin{array}{l}6.96 \\
(99.43 \\
\%)\end{array}$ & - & $\begin{array}{l}64 \\
(67 \%)\end{array}$ & \\
\hline \multicolumn{2}{|c|}{$\begin{array}{l}\text { nicorandiB } \\
\qquad(3 \%)\end{array}$} & $\begin{array}{l}8 \\
(8 \%)\end{array}$ & $\begin{array}{l}49 \\
(47 \%)\end{array}$ & $\begin{array}{l}7.00 \\
(100.00 \\
\%)\end{array}$ & $\begin{array}{l}46 \\
(98 \\
\%)\end{array}$ & $\begin{array}{l}59 \\
(62 \%)\end{array}$ & $\begin{array}{l}6.94 \\
(99.14 \\
\%)\end{array}$ & $\begin{array}{l}47 \\
(96 \\
\%)\end{array}$ & $\begin{array}{l}49 \\
(47 \%)\end{array}$ & $\begin{array}{l}6.97 \\
(99.57 \\
\%)\end{array}$ & $\begin{array}{l}45 \\
(94 \\
\%)\end{array}$ & $\begin{array}{l}57 \\
(60 \%)\end{array}$ & $\begin{array}{l}6.97 \\
(99.5 \\
\%)\end{array}$ \\
\hline \multicolumn{2}{|c|}{ ivabradin $\theta$} & 0 & $\begin{array}{l}10 \\
(10 \%)\end{array}$ & $\begin{array}{l}7.00 \\
(100.00 \\
\%)\end{array}$ & $\begin{array}{l}10 \\
(100 \\
\%)\end{array}$ & $\begin{array}{l}7 \\
(7 \%)\end{array}$ & $\begin{array}{l}7.00 \\
(100.00 \\
\%)\end{array}$ & $\begin{array}{l}6 \\
(100 \\
\%)\end{array}$ & $\begin{array}{l}10 \\
(10 \%)\end{array}$ & $\begin{array}{l}6.67 \\
(95.29 \\
\%)\end{array}$ & $\begin{array}{l}8 \\
(100 \\
\%)\end{array}$ & $\begin{array}{l}7 \\
(7 \%)\end{array}$ & \\
\hline \multicolumn{2}{|c|}{ ranolazinø } & 0 & $\begin{array}{l}6 \\
(6 \%)\end{array}$ & $\begin{array}{l}7.00 \\
(100.00 \\
\%)\end{array}$ & $\begin{array}{l}7 \\
(100 \\
\%)\end{array}$ & $\begin{array}{l}13 \\
(14 \%)\end{array}$ & $\begin{array}{l}7.00 \\
(100.00 \\
\%)\end{array}$ & $\begin{array}{l}13 \\
(100 \\
\%)\end{array}$ & $\begin{array}{l}6 \\
(6 \%)\end{array}$ & $\begin{array}{l}7.00 \\
(100.00 \\
\%)\end{array}$ & $\begin{array}{l}6 \\
(100 \\
\%)\end{array}$ & $\begin{array}{l}13 \\
(14 \%)\end{array}$ & $\begin{array}{l}6.89 \\
(98.4 \\
\%)\end{array}$ \\
\hline
\end{tabular}

Table 2 Adherence to OMT by self-report and HPLC MS/MS

Adherence to prescribed, protocol-directed cardiovascular medications as measured by self-report and HPLC MS/MS (detected). Self-reported adherence data are shown for each drug in response to the question "How many days in the preceding week did you take this medication?" A drug was 'expected' if prescribed for that patient and a urinalysis sample was tested. A drug was marked 'detected' if present in the urine on HPLC MS/MS. P-values are shown for the between groups difference in proportion of drug detected. ACEi - angiotensin converting enzyme inhibitor, AP -anti-platelet drug, ARB - angiotensin II receptor blocker, BB - beta blocker, CCB - calcium channel blocker, PCI - percutaneous coronary intervention.

\section{Discussion}

Overall adherence levels in our trial population were $>90 \%$ for almost all drugs at both pre-randomisation and follow-up, as measured by patient self-reporting of adherence and by urine HPLC MS/MS. There were no significant between-group differences at pre-randomisation or at follow-up and medication taking patterns did not change following treatment with PCI. There were no differences between self-reported and direct adherence measurement in our population, owing to near-perfect adherence levels by both measures.

Our results have shown that adherence levels in ORBITA were high in both groups at both stages, greater than is typically seen in clinical practice ${ }^{10}$ and also greater than expected for a clinical trial population ${ }^{11}$. Adherence was higher than the widely-used $80 \%$ threshold $^{12}$ for good adherence throughout, high at prerandomisation and maintained through 6 weeks of follow-up, suggesting that it was not influenced by treat- 
ment assignment to PCI or to placebo. Furthermore, adherence was maintained for all protocol-directed drugs and classes of drug and patients were therefore not selectively adherent to one class of drug or another, nor was this influenced by treatment assignment. The OMT protocol and assessments of adherence within ORBITA were designed firstly to maximise the potential therapeutic impact of guideline directed anti-anginal drugs and secondly to identify any bias or chance variation in drug usage between the PCI and placebo procedure groups. These results emphatically corroborate the findings in the main ORBITA results paper, indicating that there was no difference in drug adherence between the 2 groups that might otherwise complicate interpretation of the ORBITA trial.

Within ORBITA, two research fellows had distinct roles, and both maintained close contact with patients throughout their involvement in respective phases of the study. Patients were committed to the study, received detailed study literature and had many opportunities to ask questions and learn more about their condition and available treatment options. This created an environment that fostered good doctor-patient communication and may have promoted good medication taking behaviour, which could in part explain these very high adherence rates. Initially this took time and effort, but once patient contact had been made, implementation of the protocol was managed remotely via regular telephone clinics. This is a model that has the potential to be replicated in any clinical setting ${ }^{13,14}$. In the UK, where cardiac rehabilitation for patients with stable angina is not universally available the delivery of such a service rests with general practitioners and cardiology clinics. We are pleased to note that stable angina as an indication for cardiac rehabilitation in the UK is the subject of a themed research call by the NIHR for further clinical research ${ }^{15}$. In the interim, medication optimisation must remain a key focus for clinicians treating patients with stable angina, not least in the aftermath of the ISCHEMIA trial which reported that, with good medical therapy, there is no additional benefit of an upfront invasive strategy in stable $\mathrm{CAD}^{16}$.

In the midst of the COVID-19 pandemic outpatient consultations have moved online at a rapid pace across a multitude of medical specialties including clinical cardiology ${ }^{17,18}$. Faced with necessary social distancing measures clinicians have rapidly adapted to carrying out clinical reviews using telehealth and for many patients this has become an expected way of accessing clinical care ${ }^{19}$. The telehealth approach implemented in ORBITA provides supportive evidence of how good medication optimisation can be achieved by telephone.

There are limitations to interpretation of the adherence assessments that must be acknowledged. The HPLC MS/MS measure directly captures adherence to each drug at the time of testing but nonetheless remains vulnerable to the 'white coat adherence' phenomenon whereby patients ingest a single dose of drug just before testing to avoid detection of non-adherence ${ }^{20}$. Equally self-reported adherence is open to reporting bias $^{21}$.

Overall however, ORBITA has shown that implementation of a simple protocol of OMT is feasible and practical with limited resources. The high adherence rates seen are evidence that the OMT protocol was successfully implemented and the study methodology therefore offers a model of how optimisation can be achieved in clinical practice using telehealth.

\section{*ORBITA Study Investigators}

Rasha Al-Lamee, David Thompson, Sayan Sen, Ricardo Petraco, Christopher Cook, Yousif Ahmad, James Howard, Matthew Shun-Shin, Jamil Mayet, Jaspal Kooner, Simon Thom, Justin Davies, Darrel Francis, and Ramzi Khamis (Imperial College London, London, UK and Imperial College Healthcare NHS Trust, London, UK); Kare Tang, John Davies, and Thomas Keeble (Essex Cardiothoracic Centre, Basildon, UK); Raffi Kaprielian, Iqbal Malik, Sukhjinder Nijjer, Amarjit Sethi, Christopher Baker, Punit Ramrakha, Ravi Assomull, Rodney Foale, Nearchos Hadjiloizou, Masood Khan, Michael Bellamy, Ghada Mikhail, and Piers Clifford (Imperial College Healthcare NHS Trust, London, UK); Andrew Sharp (Royal Devon and Exeter NHS Trust, Exeter, UK); Robert Gerber (East Sussex Healthcare NHS Trust, Hastings, UK); Suneel Talwar, Peter O'Kane, Terry Levy, and Rosie Swallow (Royal Bournemouth and Christchurch NHS Trust, Bournemouth, UK); and Roland Wensel (Imperial College London, London, UK). 


\section{Declaration of Interests}

Nothing to declare.

\section{Data}

Data available on request from the authors ${ }^{22}$.

\section{Citations}

1. Al-Lamee R, Thompson D, Dehbi H-M, et al. Percutaneous coronary intervention in stable angina (ORBITA): a double-blind, randomised controlled trial. The Lancet. 2018;391(10115):31-40.

2. Management of stable angina. NICE Clinical Guidance 126 (Updated 2016). 2011. https://www.nice.org.uk/guidance/cg126/evidence/full-guideline-pdf-183176605. Accessed 27/09/2018.

3. Robert AB. Fallout from the ORBITA trial - is angioplasty in a spin?EuroIntervention : journal of EuroPCR in collaboration with the Working Group on Interventional Cardiology of the European Society of Cardiology. 2017;13(11):1253-1254.

4. Borden WB, Redberg RF, Mushlin AI, Dai D, Kaltenbach LA, Spertus JA. Patterns and Intensity of Medical Therapy in Patients Undergoing Percutaneous Coronary Intervention. JAMA. 2011;305(18):18821889.

5. Garg P, Wijeysundera HC, Yun L, Cantor WJ, Ko DT. Practice patterns and trends in the use of medical therapy in patients undergoing percutaneous coronary intervention in Ontario. Journal of the American Heart Association. 2014;3(4):e000882.

6. Elder DH, Pauriah M, Lang CC, et al. Is there a Failure to Optimize theRapy in anGina pEcToris (FORGET) study? Qjm.2010;103(5):305-310.

7. Francis DP, Davies JE, Al-lamee R, et al. Protocol 15PRT/06897:Objective Randomised Blinded Investigation with optimal medical Therapy of Angioplasty in stable angina (ORBITA trial) - NCT02062593 [Protocol]. The Lancet. 2016. http://www.thelancet.com/doi/story/10.1016/html.2016.10.12.4214. Published 13/10/2016.

8. Thom S, Poulter N, Field J, et al. Effects of a fixed-dose combination strategy on adherence and risk factors in patients with or at high risk of cvd: The umpire randomized clinical trial. JAMA.2013;310(9):918929.

9. Tomaszewski M, White C, Patel P, et al. High rates of non-adherence to antihypertensive treatment revealed by high-performance liquid chromatography-tandem mass spectrometry (HP LC-MS/MS) urine analysis. Heart. 2014.

10. Ho PM, Bryson CL, Rumsfeld JS. Medication Adherence: Its Importance in Cardiovascular Outcomes. Circulation. 2009;119(23):3028-3035.

11. Armstrong EJ, Chen DC, Westin GG, et al. Adherence to guideline-recommended therapy is associated with decreased major adverse cardiovascular events and major adverse limb events among patients with peripheral arterial disease. Journal of the American Heart Association. 2014;3(2):e000697.

12. Bansilal S, Castellano JM, Garrido E, et al. Assessing the Impact of Medication Adherence on Long-Term Cardiovascular Outcomes. Journal of the American College of Cardiology. 2016;68(8):789-801.

13. Nieuwlaat R, Wilczynski N, Navarro T, et al. Interventions for enhancing medication adherence. Cochrane Database Syst Rev.2014;11.

14. Yach D. Adherence to Long-term Therapies: Evidence for Action. In: World Health Organisation; 2003. 
15. NIHR. HTA Funding Committee Public Minutes 19-20 May 2020. 2020. https://www.nihr.ac.uk/documents/hta-funding-committee-public-minutes-19-20-may-2020/25078?pr=. Accessed 14/08/2020.

16. Maron DJ, Hochman JS, Reynolds HR, et al. Initial Invasive or Conservative Strategy for Stable Coronary Disease. N Engl J Med.2020;382(15):1395-1407.

17. Eberly LA, Khatana SAM, Nathan AS, et al. Telemedicine Outpatient Cardiovascular Care During the COVID-19 Pandemic. Circulation.2020;142(5):510-512.

18. Webster P. Virtual health care in the era of COVID-19. The Lancet. 2020;395(10231):1180-1181.

19. Hollander JE, Carr BG. Virtually Perfect? Telemedicine for Covid-19.N Engl J Med. 2020;382(18):16791681.

20. Modi AC, Ingerski LM, Rausch JR, Glauser TA, Drotar D. White Coat Adherence over the First Year of Therapy in Pediatric Epilepsy. The Journal of Pediatrics. 2012;161(4):695-699.e691.

21. Osterberg L, Blaschke T. Adherence to Medication. N Engl J Med. 2005;353(5):487-497.

22. Al-lamee R. Summary and Contact. 2020. https://www.imperial.ac.uk/people/r.al-lamee13. 